Original Article

\title{
The immediate effects of taping therapy on knee pain and depression in patients with degenerative arthritis
}

\author{
Ji-Won Han, PT ${ }^{1)}$, Dong-Kyu Lee, $\left.\mathrm{PT}^{2}\right)^{*}$, Chi-Bok Park, $\mathrm{PT}^{3)}$ \\ 1) Department of Rehabilitation Science, Graduate School, Daegu University, Republic of Korea \\ 2) Department of Physical Therapy, Sunhan Hospital: 975 Mujin-daero, Seo-gu, Gwangju 61917, \\ Republic of Korea \\ 3) Department of Physical Therapy, SKJ Hospital, Republic of Korea
}

\begin{abstract}
Purpose] This study aims to identify the immediate effects of taping therapy on knee pain and depression among patients with degenerative arthritis. [Subjects and Methods] In total, 32 patients with degenerative arthritis were randomly assigned to one of two groups: the experimental group that underwent taping therapy and the control group that underwent regular treatment (16 patients per group). In the experimental group, therapeutic tape was wrapped all around the knee joint. Pain and depression were measured using the visual analogue scale (VAS) and the Beck Depression Inventory (BDI), respectively. [Results] The intra-group comparison showed significant differences in VAS and BDI for the experimental group. The intergroup comparison showed that the differences in VAS and BDI within the experimental group appeared significant relative to the control group. [Conclusion] It was observed that taping therapy showed an immediate effect in decreasing knee pain and depression among patients with degenerative arthritis.

Key words: Taping therapy, Pain, Depression
\end{abstract}

(This article was submitted Dec. 30, 2017, and was accepted Feb. 19, 2018)

\section{INTRODUCTION}

Degenerative arthritis begins with acute degeneration of the joint cartilage, attributed to many different causes ${ }^{1)}$. As joint deformation continues, ligaments and muscles moving the joints are weakened, and the cartilage is worn out severely, with pain, ankylosis, decrease in the range of joint movement, and edema showing up as the main symptoms ${ }^{1,2)}$. Degenerative gonarthritis is a disease that can cause physical problems such as functional disorders and pain as well as decreased quality of life, causing psychosocial problems ${ }^{2}$. Taping therapy is a simple method that alleviates pain caused by degenerative arthritis, has very few side-effects, allows smooth performance of daily life activities even with the tape attached, and can be used in combination with other treatment methods ${ }^{3)}$. It also decreases muscular imbalance, pain, and muscle fatigue, while simultaneously improving neurologic functions, proprioceptive sensibility, and blood and lymph circulation ${ }^{4}$. It was especially effective in reducing pain and depression among elderly patients ${ }^{5}$. Although many studies have proven the positive effects of taping therapy, there have not been enough research that the taping therapy improves the pain and depression of degenerative arthritis patients. In view of the evidence acquired by previous studies, this study will administer taping therapy to patients with degenerative arthritis to verify its immediate effects in reducing knee pain and depression, as well as to investigate its potential as an effective treatment for degenerative arthritis.

*Corresponding author. Dong-Kyu Lee (E-mail: 1dkpt@hanmail.net)

(C2018 The Society of Physical Therapy Science. Published by IPEC Inc.

(c) $($ ) $($ This is an open-access article distributed under the terms of the Creative Commons Attribution Non-Commercial No Derivatives CC ${ }_{\text {BY NC ND }}$ (by-nc-nd) License. (CC-BY-NC-ND 4.0: https://creativecommons.org/licenses/by-nc-nd/4.0/) 
Table 1. Comparison of the results of the VAS and BDI between the experimental and control groups

\begin{tabular}{lrrrrrrrr}
\hline & \multicolumn{3}{c}{ Experimental group $(\mathrm{n}=16)$} & & \multicolumn{3}{c}{ Control group $(\mathrm{n}=16)$} \\
\cline { 2 - 3 } \cline { 6 - 8 } & \multicolumn{1}{c}{ Pre } & \multicolumn{1}{c}{ Post } & Post-pre & & \multicolumn{1}{c}{ Pre } & \multicolumn{1}{c}{ Post } & Post-pre \\
\hline VAS (scores) & $7.3(0.9)$ & $2.5(0.9)^{*}$ & $-4.8(1.1)^{\dagger}$ & & $6.9(0.9)$ & $6.2(0.9)$ & $-0.7(1.5)$ \\
BDI (scores) & $22.3(1.4)$ & $13.6(1.8)^{*}$ & $-8.7(1.7)^{\dagger}$ & & $20.9(1.7)$ & $19.1(3.9)$ & $-1.8(3.7)$ \\
\hline
\end{tabular}

Values are mean (standard deviation), VAS: Visual Analog Scale; BDI: Beck Depression Inventory.

$* \mathrm{p}<0.05$ : Significant differences between pre- and post-test, ${ }^{\dagger} \mathrm{p}<0.05$ : Significant differences between the experimental and control groups.

\section{SUBJECTS AND METHODS}

This study was conducted on 32 patients diagnosed with degenerative arthritis who were then randomly assigned to one of two groups: the experimental group and the control group. The experimental group underwent taping therapy, and the control group received regular treatment. Each group had 16 ( 8 males and 8 females) participants. They were given a detailed explanation of the purpose and method of the study, and their consent was obtained before participation. The study adhered to the principles of the Declaration of Helsinki. The ethics committee of Daegu University approved this study. The study participants selected had knee pain scores of VAS 6 or higher on the visual analogue scale (VAS), were not to receive any other treatment or therapy for pain alleviation during the study period, and were not on any pain or depression medications. For the experimental group, the average age was $63.5 \pm 5.7$ years, the average height was $162.3 \pm 7.6 \mathrm{~cm}$, and the average weight was $60.2 \pm 7.2 \mathrm{~kg}$. For the control group, the average age was $61.5 \pm 3.4$ years, the average height was $160.7 \pm 7.0 \mathrm{~cm}$, and the average weight was $58.7 \pm 6.7 \mathrm{~kg}$. Both groups received 30 minutes of thermotherapy and 20 minutes of electrotherapy. In addition, the experimental group underwent taping therapy five times a week for four weeks wherein an elastic tape was wound tightly around the knee joint and was kept on for 24 hours. Pain was measured using the visual analogue scale. The VAS is a measurement that involves a patient marking the degree of pain from 0 points to 10 points, 0 indicating no pain while 10 points indicate the most severe pain. Depression was measured using the Beck Depression Inventory (BDI). The BDI is a four-point measurement method including 21 questions. Its total scores range from 0 to 63; 9 points, 10-15 points, 16-23 points, and 24-63 points equating with no depression, mild depression, depression, and serious depression, respectively. SPSS software version 19.0 was used to statistically process and analyze the collected data. A paired t-test was performed to compare the extent of pain and depression in both groups before and after the study. An independent $\mathrm{t}$-test was used to compare differences between the groups, and statistical significance level was set at $\mathrm{p}=0.05$.

\section{RESULTS}

Changes in VAS and BDI are shown in Table 1. The intra-group comparison showed significant differences in VAS and BDI for the experimental group $(\mathrm{p}<0.05)$. The intergroup comparison showed that the differences in VAS and BDI within the experimental group appeared significant relative to the control group $(\mathrm{p}<0.05)$.

\section{DISCUSSION}

In the intra-group comparison, the experimental group showed a significant difference in VAS scores before and after the intervention that was more significant than the difference shown by the control group in the intergroup comparison. Some previous studies showed that taping therapy had an effect on decreasing pain among elderly patients and that taping was also effective in decreasing pain of patients with degenerative arthritis ${ }^{5,6)}$. When a certain area is taped with its muscles stretched, the muscles then shrink causing wrinkles and widen the space between the skin and fascia. This results in increased blood flow to the muscles, thus alleviating pain. Another reason taping therapy brings about pain alleviation is that it activates the afferent neuron responsible for apperception by sense of touch. In addition to pain, depression also decreased more significantly in the experimental group than in the control group. Kwon ${ }^{5)}$ as well as Kang and Kim ${ }^{7)}$ reported that taping therapy decreased depression, which supported the study results. Depression and pain were correlated, and pain was shown to have a negative influence ${ }^{8}$. In this study, both depression and knee pain decreased by application of taping therapy because it normalized the movements of the lower limbs for daily life activities. Not only did the pain die down, but it also made moving around much easier, and activities which were previously tedious suddenly became effortless. However, more research and development are required because controversies shroud the mechanism of taping, and its neurophysiologic theories have not been consolidated yet.

\section{Conflict of interest}

None. 


\section{REFERENCES}

1) Imhof H, Czerny C, Gahleitner A, et al.: [Coxarthrosis]. Radiologe, 2002, 42: 416-431 (In German). [Medline] [CrossRef]

2) Turner JA, Ersek M, Kemp C: Self-efficacy for managing pain is associated with disability, depression, and pain coping among retirement community residents with chronic pain. J Pain, 2005, 6: 471-479. [Medline] [CrossRef]

3) Jaraczewska E, Long C: Kinesio taping in stroke: improving functional use of the upper extremity in hemiplegia. Top Stroke Rehabil, 2006, 13: 31-42. [Medline] [CrossRef]

4) Yoshida A, Kahanov L: The effect of kinesio taping on lower trunk range of motions. Res Sports Med, 2007, 15: 103-112. [Medline] [CrossRef]

5) Kwon SS: [The effects of the taping therapy on range of motion, pain and depression in stroke patient]. Taehan Kanho Hakhoe Chi, 2003, 33: 651-658 (In Korean). [Medline]

6) Son GS, Lee MH, Lee CR, et al.: The effects of kinesio taping on the pain and functional improvement in patients with degenerative arthritis. KJSB, 2008, 18: $45-52$.

7) Kang SJ, Kim IS: Effects of a taping therapy on shoulder range of motion and pain, physical function and depression of stroke patients with hemiplegia. J Korean Acad Nurs, 2012, 24: 294-304.

8) Wells-Federman C, Arnstein P, Caudill M: Nurse-led pain management program: effect on self-efficacy, pain intensity, pain-related disability, and depressive symptoms in chronic pain patients. Pain Manag Nurs, 2002, 3: 131-140. [Medline] [CrossRef] 